\title{
Ön çapraz bağ yaralanmasına eşlik eden kıkırdak hasarı ve tedavisi
}

\section{Chondral injury and treatment associated with anterior cruciate ligament injury}

\author{
Mehmet Kaymakoğlu, Gazi Huri, Egemen Turhan, Özgür Ahmet Atay \\ Hacettepe Üniversitesi Tıp Fakültesi, Ortopedi ve Travmatoloji Anabilim Dalı, Ankara
}

\begin{abstract}
Ön çapraz bağ (ÖçB) yaralanması genelde yüksek enerjisiz bir pivot mekanizması ile oluşmasına karşın, ani pivot hareketi ile yırtılan ÖÇB sonrasında enerji dizdeki kıkırdak ve menisküs gibi yapılar tarafından sönümlenir ve bazı durumlarda bu yapılarda hasarlar oluşabilir. Menisküs hasarları genelde dikkatle değerlendirilmesine rağmen kıkırdakta oluşan özellikle okült hasarlar görüntülemede ve artroskopik muayenede atlanabilir. Yapılan çalışmalarda uygun tedavi edilmeyen kıkırdak hasarları, ameliyat sonrası dönemde en az menisküs yırtıkları kadar ağrıya neden olmakta ve hastanın rehabilitasyonunu aksatıp spora dönüşünü zorlaştırmaktadır. Bu derlemede, ÖÇB yaralanmasına eşlik eden kıkırdak hasarına nasıl yaklaşılması gerektiği ve tedavinin başarısına nasıl etki edebileceğine dikkat çekilmiştir.
\end{abstract}

Anahtar sözcükler: ön çapraz bağ; kıkırdak hasarı; artroskopi

\begin{abstract}
Although anterior cruciate ligament (ACL) injury usually occurs without a high energy pivot mechanism, the energy of trauma is absorbed by the structures such as menisci or cartilage in the knee and in some cases damage may occur in these structures. Meniscus injuries are generally evaluated carefully by orthopaedic surgeons, however especially occult injuries in cartilage can be missed in imaging and arthroscopic examination. Cartilage injuries that are not treated properly may cause as much as pain as the meniscus tears postoperatively and negatively affect rehabilitation and return to sports. In this review, attention is drawn to how to approach cartilage damage in ACL injury and how it can affect the success of treatment.
\end{abstract}

Key words: anterior cruciate ligament; cartilage injury; arthroscopy
Ö n çapraz bağ (ÖÇB) yaralanması, genç ve aktif hastalarda en sık rastlanan ortopedik yaralanmalardan biridir ve ÖÇB rekonstrüksiyonu ortopedi ve travmatoloji uzmanlarının en sık gerçekleştirdiği ilk beş operasyondan biridir. ${ }^{[1,2]}$ Bu kadar sık ve önemli bir yer tutan bu patolojinin tedavisinde başarısızlık ve revizyon oranları da iyi kliniklerde bile \%10'lara kadar yaklaşabilmektedir. ${ }^{[3]}$ Greft ile rekonstrüksiyon tekniklerindeki hataların dışında en önemli başarısızlık nedenlerinden birisi, eşlik eden meniskal veya kıkırdak yaralanmalarının tanısının atlanması ve uygun tedavisinin uygulanmamasıdır. ÖÇB yaralanması geçiren hastaların bulunduğu yaş grubunda osteoartrit nadir görülmektedir; bu nedenle diz eklemindeki kıkırdak hasarı genelde ligament veya menisküs hasarlarına bağlı kronik zeminde veya akut travma sırasında lokalize olarak gelişmektedir.
Kıkırdak rejenerasyon kapasitesi olmayan bir doku olduğu için ÖÇB yaralanması esnasında gelişebilecek kıkırdak hasarlarının gerek görüntülemede gerekse artroskopik muayenede atlanması klinik olarak ağrılı bir diz ile karşılaşmamıza neden olabilir. Shelbourne ve ark. tarafindan yapılan bir çalışmada, ÖÇB rekonstrüksiyonu sırasında menisküs ve kıkırdak hasar seviyeleri kaydedilen hastaların 5-15 yıllık takiplerinde, kıkırdak hasarı menisküs hasarından da önemli bir risk faktörü olarak rapor edilmiş ve en düşük diz skorları kıkırdak hasarı olan hastalarda bulunmuştur. ${ }^{[4]}$

\section{KIKIRDAK HASARININ TANISI VE SINIFLANDIRILMASI}

Artroskopik olarak dizdeki kıkırdak hasarını değerlendirmede Outerbridge sınıflaması kullanılmaktadır.

- İletişim adresi: Prof. Dr. Özgür Ahmet Atay, Hacettepe Tıp Fakültesi Erişkin Hastanesi Ortopedi ve Travmatoloji Anabilim Dalı Sekreterliği, 06100, Sıhhiye, Ankara Tel: 0312 - 3051209 e-posta: ozguraatay@gmail.com

- Geliş tarihi: 5 Mayıs $2020 \quad$ Kabul tarihi: 28 Mayıs 2020 
ilk olarak kondromalazi patelladaki kıkırdak hasarını değerlendirmek için 1969 yılında yayımlanan bu sınıflama daha sonra diz eklemi ve diğer eklemler için modifiye edilmiştir. ${ }^{[5-7]}$ Evre 0 lezyonlar normal kıkırdak dokuyu ifade etmek için kullanılırken, Evre 1 lezyonlarda, artroskopi probu ile yapılan muayenede hasarlı bölgedeki kıkırdakta yumuşama hissedilebilir. Evre 2 lezyonlar, kıkırdağın kalınlığının yarısı kadar subkondral kemiğe ulaşmayan $1 \mathrm{~cm}$ 'den küçük fissürlerle ve çevresinde fibrilleşen yüzeyel kıkırdak katmanı ile karakterizedir. Evre 3 lezyonlarda fissürler $1 \mathrm{~cm}$ 'den daha geniştir ve hasar subkondral kemiğe kadar ulaşmaktadır. Evre 4 lezyonlarda ise subkondral kemik tamamen ortadadır ve üzerinde kıkırdak doku kalmamıştır (Tablo 1) (Şekil 1). ${ }^{[6,8]}$

Artroskopik muayeneden önce ameliyat öncesi olarak da manyetik rezonans (MR) görüntüleme bize kıkırdak hasarının karakteri ve boyutu hakkında pek çok bilgi verebilir. MR'deki kıkırdak hasarı genel olarak Outerbridge sınıflaması esas alınarak hazırlanmıştır. ${ }^{[9]}$ MR görüntülemede T1 sekansı genellikle kıkırdak hasarı hakkında ayrıntılı görüntü sağlamaz. Yağ baskılı T2 sekansı subkondral kemik ve sinovyal dokudaki değişikliklere daha duyarlı iken, kıkırdak değerlendirmede kullanılabilir. Ancak hiyalin kıkırdak hakkında en hassas görüntülemeyi proton-ağırlıklı sekansta görebiliriz. ${ }^{[10]} \mathrm{Bu}$ sekanstaki hasarlanmayı evrelere ayıracak olursak Evre 0'da normal hiyalin kıkırdak görüntülenmekte iken, Evre 1'de kıkırdak dokuda fokal hiperintensite alanları görülür ve bu artroskopik muayenede prob ile yumuşayan kıkırdak dokuya karşılık gelmektedir. Evre 2'de kıkırdağın yüzeyinde kıkırdak kalınlığının yarısından daha azını etkileyen fibrilleşme ve erozyonun yarattığı hiperintens görünüm mevcuttur. Evre 3 lezyonlarda kıkırdak kalınlığının yarısından daha fazlasını etkileyen ve subkondral kemiğe ulaşabilen hiperintens kıkırdak alanları göze çarparken, Evre 4 lezyonlar subkondral kemikte yaygın ödem ve

Tablo 1. Outerbridge sınıflaması ${ }^{[6]}$

\begin{tabular}{ll}
\hline Evre $\mathbf{0}$ & Normal kıkırdak \\
Evre 1 & $\begin{array}{l}\text { Artroskopik prob ile muayenede yumuşaklık } \\
\text { Evre 2 }\end{array}$ \\
$\begin{array}{l}\text { Kıkırdak kalınlığının \%50'sinden az, }<1 \mathrm{~cm} \\
\text { fissürleşme, yüzeyel fibrilasyon }\end{array}$ \\
Evre 3 & $\begin{array}{l}\text { Kıkırdak kalınlığının \%50'sinden fazla, >1 cm } \\
\text { fissürleşme, yer yer subkondral kemiğin gözlenmesi }\end{array}$ \\
Evre 4 & $\begin{array}{l}\text { Subkondral kemiğin açıkta olması, tamamen hasarlı } \\
\text { kıkırdak }\end{array}$
\end{tabular}

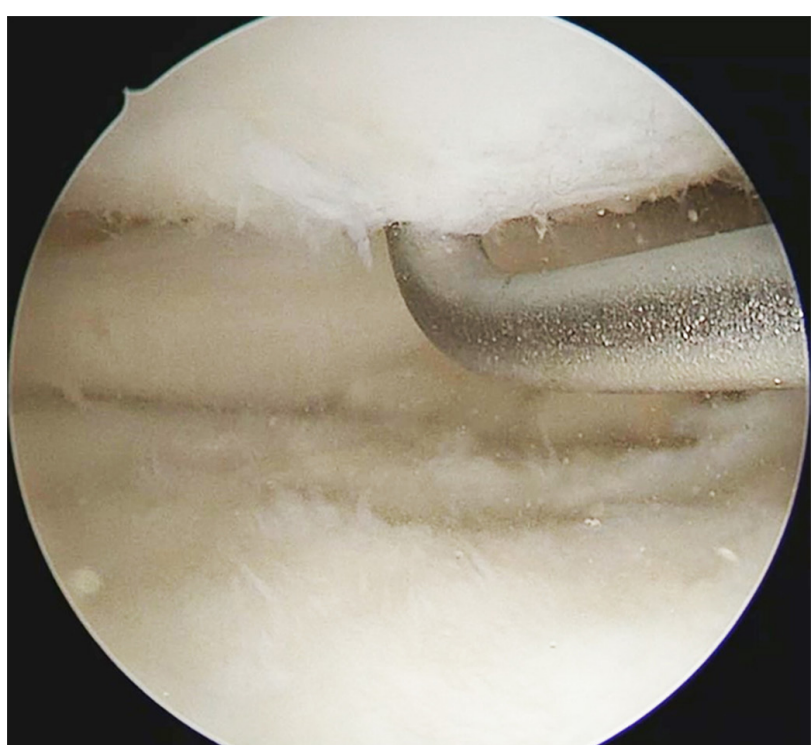

Şekil 1. Artroskopik muayenede saptanan Evre 2 lezyon.

kıkırdağın tam kat kaybı ile karakterizedir (Tablo 2) (Şekil 2). ${ }^{[11]}$ MR bazı kıkırdak lezyonlarını olduğundan daha küçük gösterebileceğinden dolayı, MR'de çok önemli bir lezyon görmesek de iyi bir artroskopik muayene yapmak şarttır.

Genel olarak kıkırdak hasarının tanısına yaklaşım bu şekilde olsa da, ÖÇB yaralanmasına eşlik eden bazı tipik kıkırdak hasarı bölgelerini de bilmemiz, ameliyat öncesi ve sırasında kıkırdak hasarını nerelerde aramamız gerektiği konusunda bize yardımcı olacaktır. ÖÇB yaralanması sırasında tibianın anteriora translasyonu ile posterolateral tibial platonun lateral kondilin sulkus terminalis bölgesine çarpması sonucu tipik bir yaralanma oluşur (Şekil 3). Bu mekanizma ile lateral diz radyografilerinde de fark edilebilen 'lateral femoral
Tablo 2. Kıkırdak hasarının MR sınıflaması ${ }^{[11]}$

\begin{tabular}{ll}
\hline Evre 0 & Normal kıkırdak \\
Evre 1 & Kıkırdakta fokal hiperintensite \\
Evre 2 & $\begin{array}{l}\text { Kıkırdak kalınlığının \%50'sine kadar olan } \\
\text { hiperintensite }\end{array}$ \\
Evre 3 & $\begin{array}{l}\text { Kıkırdak kalınlığının \%50'sinden fazla hiperintensite + } \\
\text { subkondral kemikte kemik iliği ödemi }\end{array}$ \\
Evre 4 & $\begin{array}{l}\text { Kıkırdağın tam kat kaybı + subkondral kemikte yaygın } \\
\text { kemik iliği ödemi }\end{array}$
\end{tabular}




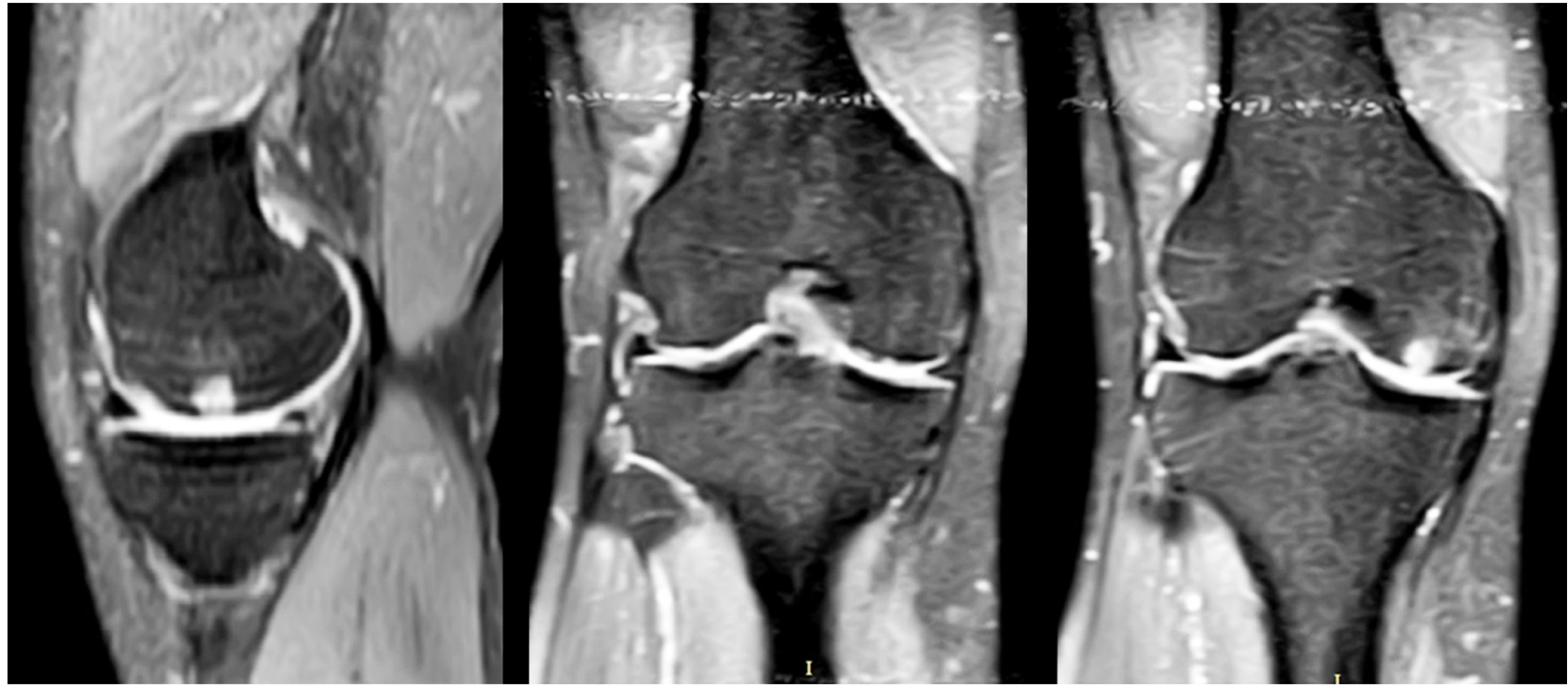

Şekil 2. MR görüntülemede, medial kondilde kronik ÖÇB yaralanmasına eşlik eden tam kat kıkırdak kaybı ve kemik iliği ödemi.

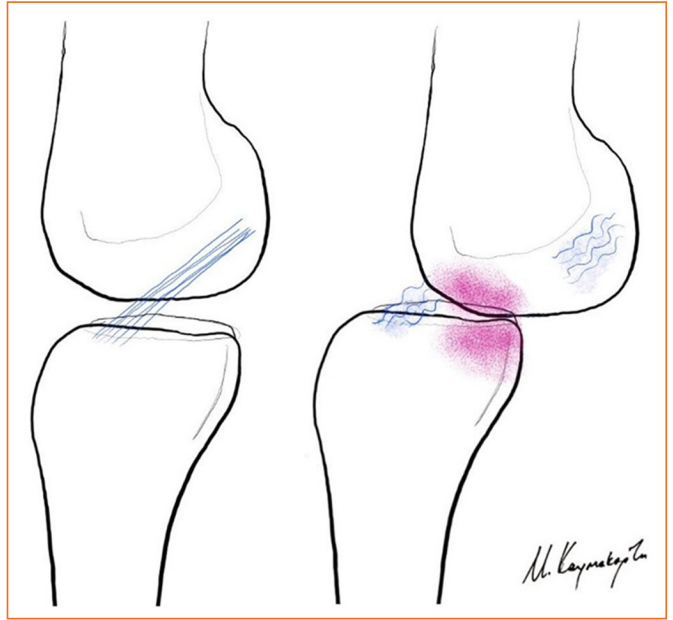

Şekil 3. ÖÇB yaralanması esnasında tibianın anteriora translasyonu ve lateral femoral kondil ile posterolateral tibial platonun impaksiyonu.

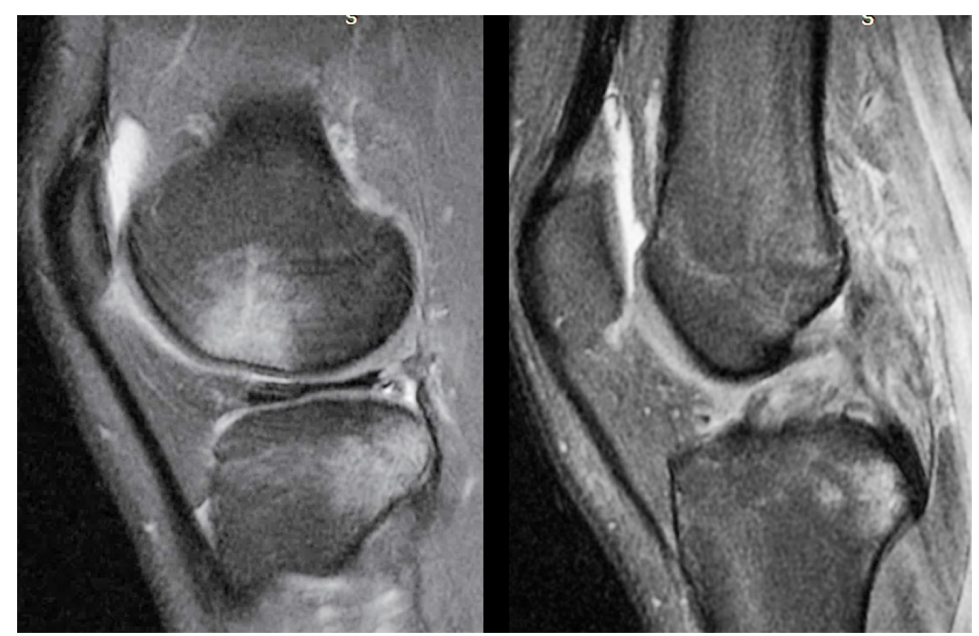

Şekil 4. MR görüntülemede, akut ÖÇB yaralanması sonrasında oluşan tipik distal lateral femoral kondil ve posterolateral tibial plato kissing lezyonları. kondil çentiği veya derin sulkus terminalis işareti' adı verilen, lateral femoral kondilde yaralanma sırasında posterior tibial platonun lateral femoral kondilde yarattığı impaksiyon ile oluşan çökme kırığı ve kıkırdak hasarı tanımlanmıştır. Bazı durumlarda muayene ile birlikte ÖÇB yaralanmasına direkt radyografide bile ön tanı konulabilir. ${ }^{[12]}$ Dikkatle değerlendirilmesi gereken diğer bir anatomik nokta ise derin sulkus terminalis işaretinin oluşmasına neden olan ve kissing lezyonu olarak adlandırabileceğimiz tibia platosunun posterolateralidir. Bu her iki noktaya ameliyat öncesi görüntülemelerde kemik ödemi ve kıkırdak hasarı açısından MR ile değerlendirmede dikkatli bir gözle bakmalı ve ameliyat sırasında da kıkırdak muayenesini unutmamalıyız (Şekil 4).

\section{KIKIRDAK HASARININ TEDAVISi}

Genel olarak kıkırdak hasarının tedavisi oldukça kapsamlı ve ayrı bir makaleyi gerektiren bir konu olsa da, kısaca ÖÇB hasarı ile ilişkisine ve tedavi yaklaşımına değineceğiz. Kıkırdak hasarının tedavisi genel olarak lezyonun büyüklügüne ve lokalizasyonuna göre değişmektedir. Ancak tüm sınıflamalardan ve 


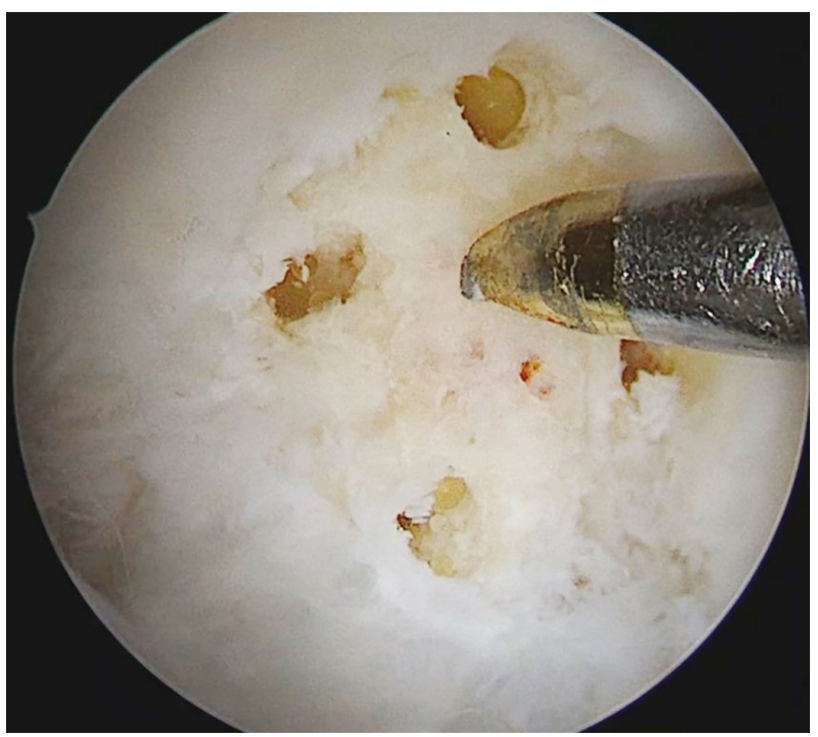

Şekil 5. ÖÇB hasarı sonrası rekonstrüksiyon uygulanan bir hastada eş zamanlı olarak kıkırdak hasarına yönelik mikro-kırık uygulaması.

tedavi seçeneklerinden önce şu bilinmelidir ki; kıkırdak hasarı olan, özellikle genç ve aktif bir hasta ise, mutlaka ÖÇB rekonstrüksiyonu ile diz biyomekaniğinin restore edilmesi gerekmektedir. Her ne kadar çok aktif olmayan ileri yaştaki hastalarda ÖÇB hasarı sonrasında dizdeki dejeneratif değişimin hızlanması tartışmalı bir konu olsa da, genç ve aktif bir hastada ağrılı bir diz ve ÖÇB yırtığı birlikte görüldüğünde her ikisinin de uygun cerrahi tedavisi iyi bir klinik sonuç için elzemdir. ${ }^{[13-15]}$

Kıkırdak hasarının $\leq 1 \mathrm{~cm}$ çapında veya $\leq 2 \mathrm{~cm}^{2}$ büyüklüğünde olduğu, Evre 1-2 olarak tanımlayabileceğimiz durumlarda mikro-kırık veya kemik iliği uyarı yöntemi denilen yöntem ile subkondral kemikte küçük delikler açılarak kemik iliğinden eklem yüzeyine gelen kök hücrelerin fibröz kıkırdak ile defekti kapatmaları ve kemik iliği ödeminin dekompresyonu sağlanır (Şekil 5). Bu yöntemin avantajı; ucuz, kolay uygulanabilir olması ve histolojik olarak hiyalin kıkırdak rejenerasyonu sağlamasa da hastaların \%60-80'inde semptomatik iyileşme sağlamasıdır. Ancak daha büyük lezyonlarda başarı şansı azalmaktadır. ${ }^{[16]}$

Hasarın $>1 \mathrm{~cm}$ boyutta olduğu veya $2-4 \mathrm{~cm}^{2}$ lik bir defekt varlığında veya Evre 1-2'den daha yüksek bir kıkırdak hasarı tespit ettiğimizde mikrokırığın başarı şansı oldukça düşmektedir. Literatürde bu büyüklükteki kıkırdak hasarlarına 'osteokondral otogreft veya mozaikplasti' adı verilen teknik ile sağlam bir kıkırdak dokunun hasarlı kıkırdak bölgesine nakli önerilmektedir. ${ }^{[17]} \mathrm{Bu}$ sağlam kıkırdak dokusu genellikle diz eklemi için lateral femoral kondilin superolaterali gibi, patella ile çok eklemleşme yapmayan ve ağırlık taşımayan bir alandan seçilmelidir. Uygun hastalar seçildiğinde mozaikplasti oldukça iyi sonuçları olan bir yöntemdir ve ÖÇB yaralanmasında da eş zamanlı başarıyla uygulandığını raporlayan pek çok yayın mevcuttur. ${ }^{[18,19]}$

Daha da büyük olan $\left(\geq 4 \mathrm{~cm}^{2}\right)$ defektler için mozaikplastide donör sahadan alınan osteokondral otogreftin çok büyük olmasından dolayı donör sahadaki morbiditesini artırdığından, kadavradan alınan osteokondral allogreft ya da hastanın kendi 'otolog kondrosit implantasyonu (OKi)' tercih edilmelidir. Riboh ve ark. tarafından kıkırdak tamir yöntemlerini karşılaştıran bir meta-analizde büyük defektlerde otolog kondrosit implantasyonunun uzun dönemde çok daha iyi klinik sonuçları olduğu belirtilmiştir. ${ }^{[20]}$ OKI'nin dezavantajı ise, kıkırdak hücresi toplanması için ek bir operasyon gerektirmesi ve maliyetinin daha yüksek olmasıdır.

Kıkırdak hasarlarına yönelik tüm bu işlemlerden sonra tıpkı ÖÇB rekonstrüksiyonundan sonra olduğu gibi breys kullanılması rutin olarak gerekli değildir ancak cerrahın tercihlerine göre gün içinde kısmi olarak kullanılabilir. ${ }^{[21,22]}$

\section{ÖÇB íLE EŞ ZAMANLI TEDAVi}

ÖÇB hasarı ile birlikte kıkırdak hasarının eş zamanlı tedavisini olgu serisi ile ilk yayımlayan Matsusue ve ark. olmuştur. ${ }^{[23]}$ Zaman içerisinde, kıkırdak hasarının büyüklügüne göre hem OKi hem de mozaikplasti ile ÖÇB rekonstrüksiyonu ile eş zamanlı çok iyi sonuçlar yayımlayan araştırmacılar olmuştur. ${ }^{[18,19,24,25]} \mathrm{Her}$ ne kadar operasyon süresi uzasa da, ek bir cerrahi gerektirmeden, ÖÇB rekonstrüksiyonu sonrasında özellikle femurdaki lezyonlar için turnikeyi indirip mini-open yöntem ile aynı seansta büyük kıkırdak hasarlarını da tamir edebiliriz. ${ }^{[26]}$ ÖÇB rekonstrüksiyonunun başarısını en az menisküs yırtıkları kadar etkileyen kıkırdak hasarlarını, hastayı ameliyata hazırlarken mutlaka o gözle değerlendirmeli, çok sık hasarlanan anatomik bölgelerde (lateral femoral kondil çentiği, posterolateral tibial plato vb.) hasar görmesek de ameliyat sırasında kıkırdağın sertliğini prob ile kontrol etmeliyiz. Unutmamalıyı ki, mikro-kırık ile bile semptomatik iyileşecek bir kıkırdak hasarı, ÖÇB rekonstrüksiyonu sonrası ağrılı ve sert bir dize neden olup, genç ve aktif hastalarda rehabilitasyonun optimum yapılmasını engelleyecek, spora dönüşü zorlaştıracak ve hasta memnuniyetini çok azaltacaktır. 


\section{KAYNAKLAR}

1. Lyman S, Koulouvaris $P$, Sherman S, Do $H$, Mandl LA, Marx RG. Epidemiology of anterior cruciate ligament reconstruction: trends, readmissions, and subsequent knee surgery. The Journal of bone and joint surgery American volume 2009;91(10):2321-8. Crossref

2. Spindler KP, Wright RW. Clinical practice. Anterior cruciate ligament tear. N Engl J Med 2008;359(20):2135-42. Crossref

3. Gans I, Retzky JS, Jones LC, Tanaka MJ. Epidemiology of Recurrent Anterior Cruciate Ligament Injuries in National Collegiate Athletic Association Sports: The Injury Surveillance Program, 2004-2014. Orthop J Sports Med 2018;6(6):2325967118777823. Crossref

4. Shelbourne KD, Gray T. Results of anterior cruciate ligament reconstruction based on meniscus and articular cartilage status at the time of surgery. Five- to fifteen-year evaluations. Am J Sports Med 2000;28(4):446-52. Crossref

5. Slattery C, Kweon CY. Classifications in Brief: Outerbridge Classification of Chondral Lesions. Clin Orthop Relat Res 2018;476(10):2101-4. https://www.ncbi.nlm.nih.gov/pmc/ articles/PMC6259817/

6. Outerbridge RE. The etiology of chondromalacia patellae. J Bone Joint Surg Br 1961;43-B(4):752-7. Crossref

7. Curl WW, Krome J, Gordon ES, Rushing J, Smith BP, Poehling GG. Cartilage injuries: a review of 31,516 knee arthroscopies. Arthroscopy 1997;13(4):456-60. Crossref

8. Noyes FR, Stabler CL. A system for grading articular cartilage lesions at arthroscopy. Am J Sports Med 1989;17(4):505-13. Crossref

9. Bachmann G, Heinrichs C, Jurgensen I, Rominger M, Scheiter A, Rau WS. Comparison of different MRT techniques in the diagnosis of degenerative cartilage diseases. In vitro study of 50 joint specimens of the knee at T1.5. Fortschr Röntgenstr 1997;166(5):429-36. Crossref

10. Schaefer FK, Kurz B, Schaefer PJ, Fuerst M, Hedderich J, Graessner J, Schuenke M, Heller H. Accuracy and precision in the detection of articular cartilage lesions using magnetic resonance imaging at 15 Tesla in an in vitro study with orthopedic and histopathologic correlation. Acta Radiol 2007;48(10):1131-7. Crossref

11. Rodrigues MB, Camanho GL. MRI evaluation of knee cartilage. Rev Bras Ortop 2015;45(4):340-6. Crossref

12. Herbst E, Hoser C, Tecklenburg K, Filipovic M, Dallapozza C, Herbort M, Fink C. The lateral femoral notch sign following ACL injury: frequency, morphology and relation to meniscal injury and sports activity. Knee Surg Sports Traumatol Arthrosc 2015;23(8):2250-8. Crossref

13. Kessler MA, Behrend $H$, Henz S, Stutz G, Rukavina A, Kuster MS. Function, osteoarthritis and activity after ACLrupture:11 years follow-up results of conservative versus reconstructive treatment. Knee Surg Sports Traumatol Arthrosc 2008;16(5):442-8. Crossref
14. Barenius B, Ponzer S, Shalabi A, Bujak R, Norlen L, Eriksson K. Increased risk of osteoarthritis after anterior cruciate ligament reconstruction: a 14-year follow-up study of a randomized controlled trial. Am J Sports Med 2014;42(5):1049-57. Crossref

15. Ajuied A, Wong F, Smith C, Norris M, Earnshaw P, Back D, Davies A. Anterior cruciate ligament injury and radiologic progression of knee osteoarthritis: a systematic review and meta-analysis. Am J Sports Med 2014;42(9):2242-52. Crossref

16. Orth $\mathrm{P}$, Gao L, Madry H. Microfracture for cartilage repair in the knee: a systematic review of the contemporary literature. Knee Surg Sports Traumatol Arthrosc 2020;28(3):670-706. Crossref

17. Robert H. Chondral repair of the knee joint using mosaicplasty. Orthop Traumatol Surg Res 2011;97(4):418-29. Crossref

18. Oztürk A, Ozdemir MR, Ozkan Y. Osteochondral autografting (mosaicplasty) in grade IV cartilage defects in the knee joint:2to 7-year results. Int Orthop 2006;30(3):200-4. Crossref

19. Panics G, Hangody LR, Balo E, Vasarhelyi G, Gal T, Hangody L. Osteochondral Autograft and Mosaicplasty in the Football (Soccer) Athlete. Cartilage 2012;3(1 Suppl):25S-30S. Crossref

20. Riboh JC, Cvetanovich GL, Cole BJ, Yanke AB. Comparative efficacy of cartilage repair procedures in the knee: a network meta-analysis. Knee Surg Sports Traumatol Arthrosc 2017;25(12):3786-99. Crossref

21. Kinikli G, Callaghan M, Parkes M, Yuksel I. Bracing After Anterior Cruciate Ligament Reconstruction: Systematic Review and Meta-Analysis. Turkiye Klinikleri J Sports Sci 2014;6(1):28-38. https://www.turkiyeklinikleri.com/article/ tr-bracing-after-anterior-cruciate-ligament-reconstructionsystematic-review-and-meta-analysis-68540.html

22. Yang XG, Feng JT, He X, Wang F, Hu YC. The effect of knee bracing on the knee function and stability following anterior cruciate ligament reconstruction: A systematic review and meta-analysis of randomized controlled trials. Orthop Traumatol Surg Res 2019;105(6):1107-14. Crossref

23. Matsusue $\mathrm{Y}$, Yamamuro $\mathrm{T}$, Hama $\mathrm{H}$. Arthroscopic multiple osteochondral transplantation to the chondral defect in the knee associated with anterior cruciate ligament disruption. Arthroscopy 1993;9(3):318-21. Crossref

24. Peterson L, Minas $T$, Brittberg $M$, Lindahl A. Treatment of osteochondritis dissecans of the knee with autologous chondrocyte transplantation: results at two to ten years. J Bone Joint Surg Am 2003;85(Suppl 2):17-24. Crossref

25. Amin AA, Bartlett $W$, Gooding $C R$, Sood $M$, Skinner JA, Carrington RWJ, Briggs R, Bentley G. The use of autologous chondrocyte implantation following and combined with anterior cruciate ligament reconstruction. Int Orthop 2006;30(1):48-53. Crossref

26. Bartha L, Vajda A, Duska Z, Rahmeh H, Hangody L. Autologous Osteochondral Mosaicplasty Grafting. J Orthop Sports Phys Ther 2006;36(10):739-50. Crossref 